\title{
PROCESSES LEADING TO INFRA-GRAVITY PERIOD OSCILLATIONS AND CURRENTS IN PORTS AND MARINAS
}

\author{
Charitha Pattiaratchi, The University of Western Australia, chari.pattiaratchi@uwa.edu.au \\ Sarath Wijeratne The University of Western Australia, sarath.wijeratne@uwa.edu.au
}

\begin{abstract}
INTRODUCTION
In this paper, we take the broad definition of tsunami ('harbour wave') to describe oscillations in the infragravity (IG) periods (between 30 and 300s) in ports and marinas that often lead to interruption in harbour operations due to excessive vessel movements. The main processes that lead to these oscillations (also called seiches) are examined through the analysis of field measurements of water levels and currents from Western Australia.
\end{abstract}

In a port or marina with lengths of the order of $500 \mathrm{~m}$ and depths of the order of $10 \mathrm{~m}$, the natural oscillation periods are of the order of a few minutes. Changes in water levels in the coastal ocean adjacent to the port can setup oscillations within the port at its natural frequency. This results in water level fluctuations and strong horizontal currents within the port. If the incoming forcing is close to the natural frequency of oscillation resonance conditions may arise resulting in increased agitation inside the port. In addition if the harbour oscillation periods coincide with natural period of moored vessels, harbour operations can be severely interrupted due to strong vessel movements damaging to mooring lines and fenders.

Harbour oscillations occur either as 'free' or 'forced' oscillations depending on the natural period of oscillation (NOP) and periods contained in the external forcing. 'Free' oscillations occur in ports when the external force changes the water level in the harbour beyond its equilibrium position. Gravity attempts to restore the water level to the equilibrium level but oscillations of the port at the NOP continues after the cessation of the initial forcing until the system eventually reaches to an equilibrium position (Rabinovich, 2009). The main causes of these types of oscillations are due to meteorological and seismic tsunamis. 'Forced oscillations occur when the port is continuously forced with external forcing at periods that does not include the NOP of the port. Here, the amplitude of the oscillation depends on the proximity of the external forcing frequency to the port NOP (Rabinovich, 2009). Forced oscillations cannot persist (or is rapidly attenuated) after the cessation of the external force. When the main period of the external forcing coincide with the NOP natural frequencies of the harbour, the amplitudes of the oscillations are highly amplified. This phenomenon is known as 'resonance'. Thus ocean waves, arriving at the entrance of a an enclosed or semi-enclosed water body (bay, gulf, inlet, fjord, or port), normally consist of a broad frequency spectrum that spans the response of the water body from resonantly generated free modes to nonresonantly forced oscillations at other frequencies. Following cessation of the external forcing, forced oscillations normally decay rapidly, while free modes can persist for a considerable time (Rabinovich, 2009).
The processes that are examined in this paper include:

(1) Surface gravity waves. Many studies have suggested that swell waves propagate as well-defined groups from deep water to water depths less than a few meters and significant amount of wave energy can be transferred from the wind waves to the IG waves. This implies that IG wave energy is generally low in deep water and increases where the depth decreases such as near offshore reefs and at the shoreline (Thotagamuwage and Pattiaratchi 2014b). Data from continuously recording pressure sensors (RBR Solo recording at $2 \mathrm{~Hz}$ ) were analysed to examine the periods of contained in the offshore. Results indicated that a range of processes (periods) were present and included (Figure 1) tides (24 and 12 hours), continental shelf seiche (1.7 hours), infra-gravity waves (30-300s), and surface gravity waves (6 to 15 s).

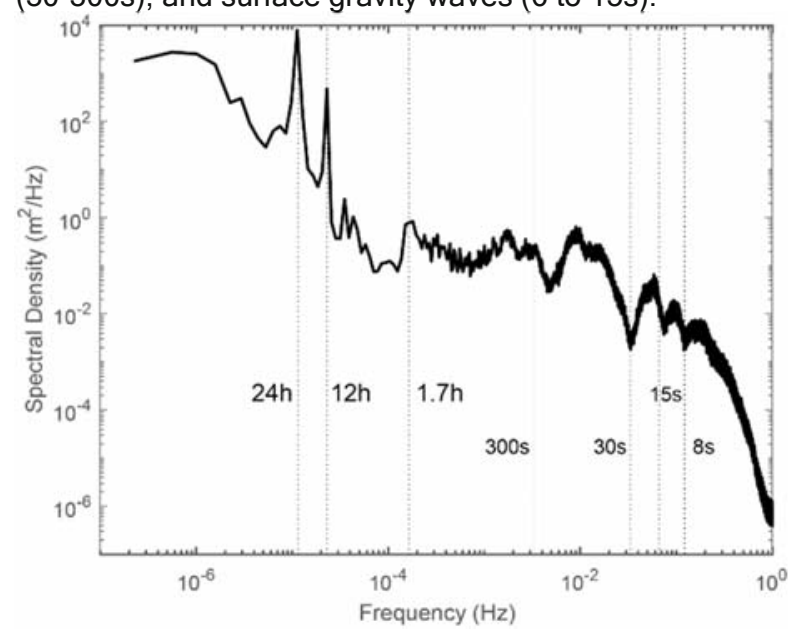

Figure 1 - Power spectrum of data collected continuously at $2 \mathrm{~Hz}$ over a 3 month period off Western Australia showing the range of frequencies from tides to sea waves.

Time-frequency plot of spectral energy from the pressure record indicated a correspondence between long period swell events (periods > 15s) and IG energy in the 30-300s period (Figure 2). Closer examination of the data indicated a strong relationship between IG waves and wind waves in different bands (sea < 8s; swell 8-15s; long period swell $>15$ ). The results indicated that IG energy was: (1) present throughout the year with maxima during winter; (2) negligible during local storms under low swell conditions; (3) always associated with swell waves; and, (4) enhanced during storm events when the local sea waves interacted with swell waves. There were strong linear relationships with swell and IG wave heights. This incident wave climate set-up oscillations within ports and marinas in the region 


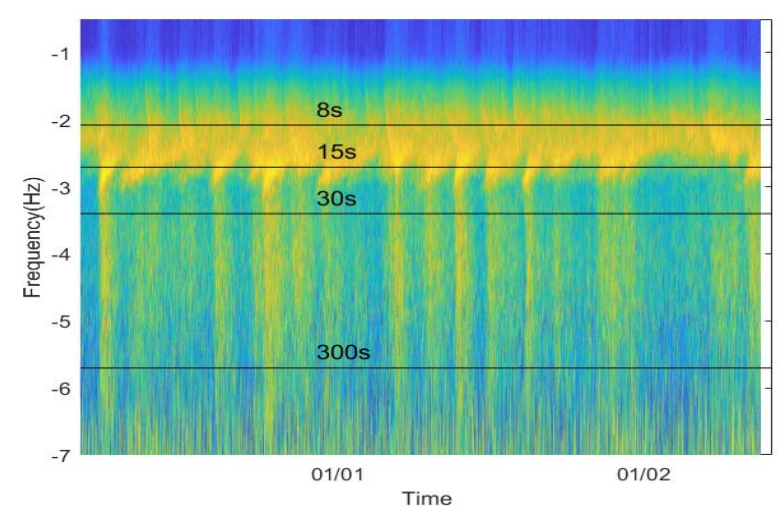

Figure 2 - Time-frequency plot of spectral energy from pressure data collected continuously at $2 \mathrm{~Hz}$ over a 3 month period off Western Australia showing relationship between long period swell events (periods $>15 s$ ) and IG energy in 30-300s period.

(2) Seismic tsunamis (origin of the name tsunami for harbour waves). Tsunamis are generated through seismic activity (undersea earthquakes being the most common). Due to shoaling induced increased wave heights tsunamis can cause extensive damage in coastal regions through inundation. An additional feature is the generation of oscillations in bays and harbours that can persist for few days after the tsunami impact (Rabinovich, 2009; Pattiaratchi and Wijeratne, 2009). Water level data obtained during the 2004 Indian Ocean tsunami indicated that the harbour oscillations lasted more than 3 days after tsunami impact (Figure 1).

(3) Meteorological tsunamis are water level oscillations with similar characteristics to tsunami waves, but are generated by meteorological events. Sea level records have shown that meteotsunamis are a regular occurrence in the region occurs all year but there is seasonality in the forcing mechanisms. During the summer months, meteotsunamis are generated by thunderstorm activity and tropical cyclone forcing and during the winter months through the passage of cold fronts. Although meteotsunamis were generated by transiting atmospheric pressure jumps the resulting wave forms from the various mechanisms were different. Meteotsunamis generated by the passage of cold fronts induced oscillations inside harbours that lasted longer than those due to thunderstorms or tropical cyclones. Water level data obtained during a meteotsunami event in 2002 indicated that the harbour oscillations lasted $\sim 1$ day after the event (Figure 1). A meteotsunami event due to the passage of a cold front resulted in a ship breaking moorings in Fremantle Port and impacting on a railway bridge was attributed to a meteotsunami (Pattiaratchi and Wijeratne, 2015).

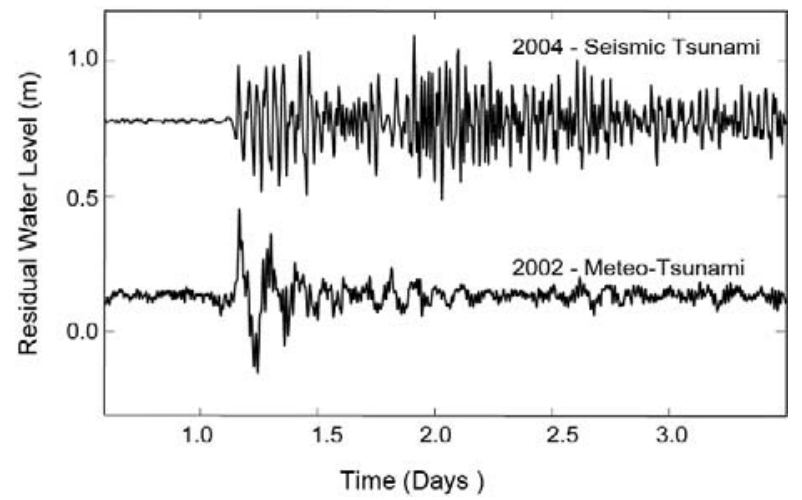

Figure 3 - Time series of residual water level (filtered to include periods $<6$ hours) recorded at Fremantle Boat Harbour during the 2004 Indian Ocean Tsunami and a Meteotsunami recorded in 2002

\section{REFERENCES}

Pattiaratchi and Wijeratne (2009), Tide gauge observations of the 2004-2007 Indian Ocean tsunamis from Sri Lanka and Western Australia, Pure and Applied Geophysics, 166, 1-2, 233-258.

Pattiaratchi and Wijeratne, (2015). Are meteotsunamis an underrated hazard? Philosophical Transactions Royal Society of London A. doi:10.1098/rsta.2014.0377.

Rabinovich (2009), Seiches and harbour oscillations, in Handbook of Coastal and Ocean Engineering, edited by Y. C. Kim, pp. 193-236, World Scientific Publishing Co., Singapore.

Thotagamuwage DT \& Pattiaratchi CB. 2014a. Observations of infragravity period oscillations in a small marina. Ocean Engineering, 88, 435-445.

Thotagamuwage DT \& Pattiaratchi CB. 2014b. Influence of offshore topography on infragravity period oscillations in Two Rocks Marina, Western Australia. Coastal Engineering, 91, 220-230. 